\title{
IMPROVING THE INTERNATIONAL LEGISLATIVE PROCESS
}

\section{Paul C. Szasz*}

\section{INTRODUCTION}

It is surely an interesting commentary on the perception of academic international lawyers, that innumerable studies, despairing comments and impractical proposals have been written about the essentially moribund international judicial process and equally about the feeble international executive-resulting in a generally negative lay perception of both the activities and the potentialities of international law and international government. On the other hand, far less is being published about the relatively vigorous international administrative process, though which, inter alia, assistance worth billions of dollars is being distributed annually, and still less about the international legislative process by which an increasingly substantial amount of international law is steadily being created. ${ }^{1}$ Indeed, because the greatest part of such law relates to unfamiliar technical areas-which of course is equally true of domestic legislation - the process by which it is produced has remained generally unknown, unappreciated, unstudied and unimproved.

In the course of attempting to establish an inventory of significant multilateral treaties (the principal, though by no means the sole expressions of international law), this author and a colleague have identified well over a thousand such instruments. Though a few are just over a century old, the greatest bulk is of post-World War II vintage. Currently well over a score of such instruments are being promulgated each year and the general trend is upwards. Taking as an example 1976, as the last year for which reasonably complete information is available, at least 26 significant multilateral agreements were concluded, of which about a third are potentially universal (i.e., open to all or almost all states) and several others are also of a world-wide scope (though not of poten-

\footnotetext{
- Principal Officer, Office of the Legal Counsel, United Nations. The views expressed herein are not necessarily those of the United Nations.

${ }^{1}$ One of the few essays on this subject is one recently published by the Legal Counsel of the United Nations, Mr. Erik Suy, Innovations in International Law-Making Processes, in The International Law and Policy of Human Welfare 187 (1978).
} 
tial interest to most states), while about half are regional. At least five of these multilateral agreements established new international organizations, such as the International Fund for Agricultural Development (IFAD), the International Maritime Satellite Organization (INMARSAT) and the International Rubber Council; six concerned environmental protection, including that of the high sea, the Mediterranean and the river Rhine; two concerned commodities; wheat and rubber; three were labor conventions promulgated by the International Labour Organisation (ILO); three concerned cultural questions, such as the importation of educational, scientific and cultural materials, the reciprocal recognition of diplomas and the protection of the archeological and historical heritage of the Americas; finally, some dealt with a miscellany of subjects, such as space exploration, plurilingual extracts of civil status records, the limitation of liability for maritime claims, the regulations of a regional trade area and regional postal matters.

One reason, and one to which I shall revert several times, why the international legislative process is so inadequately known and insufficiently appreciated is that the arrangements for recording and publicizing its products are so inadequate. There is no official journal, nor any public or private source that systematically reports on the promulgation of new multilateral treaties. Worse yet, there exists no general compendium of all such treaties, and still less any even rudimentary codification of international public law as established by treaties. ${ }^{2}$ Thus, it is most difficult to compile, without considerable research and often the need for some luck or special connections, a complete list of treaties in a given field (e.g., human rights, environmental protection, constitutions of intergovernmental organizations, maritime matters), and even after particular treaties are identified, there is no ready way to obtain an up-to-date list of the parties to many of them or even to determine whether they are already, or still, in force. It can only be hoped that the next decades will see a marked improvement in the documentation of international law, which is seriously defective in practically all respects, as this is a development that can, unlike others relating to the international governmental process, be achieved without major political decisions and by the mere ap-

\footnotetext{
2 Such a project was suggested by C.W. Jenks in The Conflict of Law-making Treaties, 30 BRIT. Y.B. INT"L L. 401 (1953), in which he also complained that "[e]ven the texts [of treaties] currently in force are not conveniently available." Id at 431.
} 
plication of sufficient resources. If necessary, it even could be done on a private, academic basis should intergovernmental institutions not take up the challenge.

To assert that the international legislative process functions, and perhaps functions better than most other international governmental procedures, is not to claim that this process is already perfect or even satisfactory. Indeed, it is imperfect in several senses of the word: for example, the output of multilateral treaties is clearly not adequate to govern any substantial fraction of the matters requiring such regulation by international law; furthermore, to the extent treaties are produced they frequently deal inadequately with the problems to which they are addressed. In addition to these imperfections, which are of course also more or less characteristic of the better established, integrated and known national and local legislatures, there is one defect peculiar to the international process: even after a treaty is adopted by a collective decision, it does not enter into force until individually accepted by a specified number of states, and even then it is, with rare exceptions, not binding except on those states that have so accepted it. This essay will consider in what ways and to what extent this international process is actually susceptible of amelioration under some reasonable hypotheses of good sense and good will, and to what extent certain improvements would require such drastic changes in international relations and procedures that they cannot be anticipated within the present generation.

While the emphasis herein will be on that aspect of the international legislative process that proceeds through the formulation of multilateral treaties, primarily those concluded on a universal or at least a world-wide basis but also including significant regional instruments, it should be recognized that there are also other devices by which a limited body of international law is being produced, which perhaps may be used more extensively in the future. These include: the conclusion of series of similarly formulated bilateral or restricted multilateral treaties, if these are sufficiently numerous and substantively uniform; the articulation and evocation of general principles of international law through resolutions of sufficiently representative and authoritative international organs, though this is at best a slow, uncertain and controversial process; the slowly growing number of examples of certain technical international institutions that have regulation-making competence in limited areas; and finally the creation by inter- 
governmental organizations of a body of international administrative law, which is itself rapidly developing but necessarily of quite limited scope.

Turning now again to the treaty-making bodies, we find that these include several in the United Nations, especially the General Assembly and the Economic and Social Council, as well as many of their subsidiary organs such as standing and ad hoc committees of the Assembly and the regional and functional commissions of ECOSOC; specialized and related agencies, including those, like ILO, IMCO, or WIPO, that are primarily involved in treaty-making and administration, and those, like the World Bank, WHO, or the IAEA, that only occasionally venture into this field; other world-wide organizations, such as the Customs Cooperation Council (CCC), various fisheries commissions and commodity councils; and regional agencies, including primarily political ones such as the Council of Europe, the Organization of American States, the Organization for African Unity and the League of Arab States, and economic ones such as OECD, COMECON and LAFTA. In addition, individual governments from time to time resume a function that was peculiary theirs before the advent of international organizations, by proposing the conclusion of a treaty for some purpose and convening an international conference therefor.

A contemplation of this plethora of more or less specialized lawmaking organs immediately suggests why the international legislative process is highly unsystematic and decentralized and that, indeed, these characteristics are at once a reason for its relative obscurity and for at least some of its imperfections. One likely line of improvement that therefore comes to mind, even before examining the details of the various stages of the process, is the achievement of a greater degree of coherence and centralization. This might best be accomplished through the General Assembly of the United Nations, at least in respect of all universal and world-wide treaties. Political realities being what they are-and it should be appreciated that current international dynamics involves not only the interaction of nation-states but also of international organizations, even though these may have substantially identical memberships - it seems unlikely that effective centralization can be achieved in the immediate future. But if the international community becomes more alert to this problem, and there are some indications that this is happening, it would logically be the United Nations that would assume at least a significant coordinating role. In the first place, this could involve 
the regular gathering and dissemination of up-to-date information about the activities of all stages of the legislative process in various international fora: what subjects are under study by each treaty-making organ; what multilateral treaties are in the course of being formulated; what treaties have been promulgated; and what state action has taken place or is contemplated in respect of all promulgated treaties, whether or not already in force. In the second place, and this is an enterprise on which the General Assembly has recently though only tentatively embarked,$^{3}$ the treaty-making process should be studied, at least with a view to discovering whether any of the multitude of methods used are superior to others and whether certain successful ones developed in a particular context or in respect of a particular agreement can be generalized. Though it is the United Nations that is naturally called on to play such a central and coordinating role, there is no reason why its activities in this respect cannot be reinforced or supplemented by other entities, including private ones, which may even take the lead if the enterprise or the resources of the public agencies should falter.

\section{The Multilateral Treaty-making Process}

In embarking now on a brief analysis of the multilateral treatymaking process, it will be convenient to concentrate on several stages in particular: the initiation of the process; the method of formulating treaties; their adoption; and post-adoption activities. It should, however, be realized that there is a degree of artificiality in such a division and that to a considerable extent these stages, particularly the first three, overlap.

\section{A. INITIATION}

The initiation of the legislative process is generally an unsystematic affair even on the national level, though less so where the legislative initiative is in practice mostly exercised by the executive. On the international level the diversity of initiatives is even greater, both because of the highly decentralized nature of the entire process (which is not characteristic of national legislatures) and because of the dearth of cumulative and up-todate information about treaty-making.

${ }^{3}$ G.A. Res. 32/48, Dec. 8, 1977, Review of the Multilateral Treaty-making Process. A report by the Secretary-General in response to this resolution is due in 1980, which is to be considered at 35th regular session of the General Assembly. 
That some coordination would be valuable is suggested by several considerations. One is the desirability of creating as coherent a body of international law as possible, avoiding both gaps and overlaps between instruments relevant to the same field. Another is the need to assure at least some efficiency and rationality for the process, since the need for international law is great and increasing as the number of states grows and the world becomes more interdependent, while the resources required to formulate that law remain limited; it would be sensible, therefore, to establish priorities, taking into account the areas in which new law is particularly needed, the likely difficulty in achieving such law, the most appropriate organ for undertaking that work (depending on whether it should be a universal, worldwide or regional agency and on whether it should be a technical or a primarily political one) and whether a standing body or an ad hoc one appears most suitable.

As already pointed out, in order to permit informed conclusions about the aspects of international intercourse in which new law is needed, the existing legislative texts should be readily available. They should be supplemented not only by current information about newly adopted instruments but also by data about instruments already in the process of being formulated. To make informed proposals about the best method of formulating a treaty in a given area, it is necessary to have available information about the activities and procedures of many different legislative bodies. To permit effective coordination to take place, some agency, presumably a subsidiary body of the U.N. General Assembly, would have to absorb these data and develop these proposals. Emphasis could be given to these proposals through endorsements by the General Assembly in the form of recommendations addressed both to the intergovernmental organizations concerned and to the states of the world community, which ultimately control all these organizations.

\section{B. FORMULATION}

The most complicated and diverse stage in the treaty-making process is, of course, that of formulating the instruments. This may involve several sub-stages: preliminary studies, particularly in technically complex fields; the preparation of initial drafts by the secretariat of the competent organization, by a government or group of governments, by a non-governmental organiza- 
tion, by an expert body, by a representative body with restricted membership, or even (though this is generally not practical) by a plenary political body; finally, the consideration and development of those drafts may be undertaken in a succession of organs, generally starting with small, expert and sometimes ad hoc ones and moving to larger, more political and less specialized ones. Throughout this stage there may be direct consultations with governments, which supplement the deliberations of political organs constituted of national representatives.

As this description suggests, this stage can by a very long one, though its duration naturally depends, as in national legislatures, on the complexity of the subject and the strength and diversity of the views about it. In some instances, when a matter is considered urgent and essentially non-controversial, a treaty may be formulated in one or two steps taking only several weeks or months. In others, formulation may take half a generation or longer, or, indeed, not succeed at all; but in this, again, the international legislative process is by no means unique.

One of the limitations of this stage, particularly under present conditions, is the lack of sufficient manpower. Governments, especially the smaller ones, frequently complain that they are unable to keep up with the plethora of treaty-making activities, that is, they cannot supply sufficient representatives and experts to all the meetings and cannot properly review the many treaty proposals pending at any given time. A less serious constraint, but still a significant one, is the capacity of the secretariats of the international organizations concerned, which must prepare the necessary studies and drafts, solicit and analyze governmental responses and service the meetings of expert and political bodies. As the legislative agenda grows, the related budgetary requirements of the organizations also increase, both for their secretariats and for these meetings. While it may seem anomalous that treaties for which there is a perceived need should languish at this stage (or perhaps before it, if it is decided to assign them a low priority in view of more urgent projects), the limited capacity of the international legislative machinery must be recognized and taken into account.

The capacity of the world community to formulate legislation will be expanded in part as more and more lawyers, particularly in the developing countries, are trained to contribute to the process, as members of international secretariats, as experts, as governmental representatives or as national officials charged with evaluating 
treaty proposals. Meanwhile, but even after this expansion has taken place, the formulation of multilateral treaties should be made as efficient as is compatible with the political and technical difficulties inherent in the process, which often requires extended time for negotiation, reflection and study in order to achieve satisfactory results and general agreement. It can certainly not be asserted that the present process is efficient: there are far too many bodies, both standing and ad hoc. Many of these are specialized, convened for individual sessions of essentially arbitrary duration (often determined by budgetary or scheduling considerations) to deliberate on a particular instrument for the time allotted, only to stop their work repeatedly and to restart it again (after wasteful formalities) at subsequent sessions. It seems likely that fewer bodies, meeting for longer periods or in effect permanently, as do many national legislatures, could consider several instruments simultaneously and continue working on each until either a generally satisfactory text is achieved that can be submitted to the next sub-stage (e.g., governmental comments or discussion by a plenary representative body) or until a temporary impasse is reached. Aside from other advantages of such a method, experience shows that when a number of persons, even if representing widely diverse interests or ideologies, work together for extended periods in an organ or on a project, they tend to evolve more productive working relationships than strangers meeting episodically for brief intervals. Moreover, broader agendas, while possibly distracting, do give wider scope for reaching compromises through the trading of concessions on a variety of items. The examples of national and local legislatures suggests that narrow specialization is the exception and that most of these bodies deal, more or less simultaneously, with a broad range of subjects.

One relatively recent development, which might enhance the efficiency of the international legislative process, is the emergence, particularly within the United Nations and its related organizations, of ever firmer and better disciplined regional and other groupings. Naturally there are certain drawbacks to this phenomenon: at international gatherings, whether these are sessions of organs or conferences, an ever-increasing portion of the schedule is consumed by unofficial meetings rather than by official ones at which all participants are represented; only after each group's position has evolved does the inter-group bargaining begin. Furthermore, the largest of these groups, that of the 
developing states (sometimes called the Group of 77), 4 can, when united, so substantially outvote all the other groups as to discourage further bargaining under certain circumstances. For example, if the participation of the out-voted groups is not considered essential, or if it can in any event be assured by the application of extraneous pressures, there is likely to be little bargaining. Nevertheless, for the most part this "partification" of the international political process can be welcomed as considerably enhancing its coherence. Individual delegations are less apt to seek special ends reflecting merely the particular quirk of an uninstructed delegate or an uninformed official in a national capital. Moreover, the inter-group bargaining can be considerably shortened when carried out principally by group spokesmen. Though sometimes the latter represent the more radical, uncompromising wings of their group, for the most part leadership tends to the moderates, who are intent on achieving results rather than Pyrrhic political victories. It is yet too yearly to determine whether the positive aspects of this development will generally outweigh the negative ones, but the present signs are encouraging.

Another development worthy of notice, and of encouragement, is the increased participation - naturally always in an advisory rather than a decision-making role-of observers admitted to some or all of the sub-stages of treaty formulation. Some of these entities are essentially political, such as liberation movements acting as surrogate representatives of a future state, but, for the most part, they are expert international intergovernmental or nongovernmental organizations that can give considerable substantive assistance in technical deliberations.

\section{ADOPTION}

Throughout the stage of formulation, decisions must from time to time be made in the several organs in which the treaty is evolving, but these are preliminary and taken with a view to the final adoption and subsequent promulgation of the instrument. This normally takes place either in the plenary of the most representative organ of the body concerned (e.g., the General Assembly of the United Nations, the General Conference of ILO, the Con-

\footnotetext{
4 From the number of these states represented among the 120 participants in the first UNCTAD Conference in 1964; by now their number exceeds 110 , that is over two-thirds of the some 155 states participating in international organizations.
} 
sultative Assembly and the Committee of Ministers of the Council of Europe or a ministerial meeting of a U.N. regional economic commission), or at an ad hoc plenipotentiary conference convened by such an organ. It does not, indeed, make a great deal of difference which of these types of fora is chosen. A decision may depend on such factors as the competent organ's agenda and the anticipated difficulty of the final stage-i.e., whether a text has been fully agreed, requiring only its formal adoption, or whether a substantial amount of negotiation remains to be done.

More important than the formal designation of the body in which final adoption takes place are its composition and its decision-making procedures. As to the former, in most instances the body is constituted so as to be representative of all potential parties to the treaty, though there may be minor exceptions. For example, the General Assembly often adopts treaties open to "all States," including non-members such as Switzerland and the two Koreas.

As for decision-making, the general formula rule that has emerged in the post-World War II period is adoption by a twothirds majority of those voting for or against (but excluding from the count abstainers, non-participants and absentees), with each participating state entitled to cast a single vote. Major exceptions include the ILO, with its tripartite representation of governments, employers and workers; the financial institutions (such as the World Bank), where votes are weighted roughly in accordance with capital subscriptions; and organizations, such as OECD, that follow a strict unanimity rule. The general rule, however, is coming under more and more criticism as the discrepancy in size and power of states widens; smaller states are emerging, are being recognized, and are being admitted to international organizations. In addition, the size of the virtually automatic majority that can be mobilized by the developing states (many of which are the new mini- and micro-states) has increased.

Naturally; proposals have been made for the adoption of some means of weighted voting that would more "properly" reflect the "significance" of the parties aligned on one side or another of international issues. The first obstacle to such a change is of course political; as the great majority of the states at present voting in international organizations considers that it benefits from the existing rules, no voluntary change is likely and probably no involuntary one could be imposed. Perhaps still more serious is the 
likely impossibility of agreeing on any weighting formula. One based on population (exemplified by the United States Supreme Court's "one man one vote" rule), would give China some $25 \%$ of all votes, four times as many as the United States would command. Military power is not readily measurable, and basing voting strength on it would but increase the arms race. Economic power would suit the Western states but hardly anyone else, for political, ideological and perhaps even moral reasons. The size of contributions to the organization, both assessed and voluntary, would seem ideal and perhaps stimulative of largesse, but politically this too is a non-starter. One compromise advanced by academic observers is a multi-chambered system, analogous to the United States Congress, where in one chamber each state would have one vote (thereby preserving the principle of sovereign equality) while in on one or more others some type of weighting would be used. In fact, as long as all of these chambers consist of instructed representatives, unlike those in either House of the United States Congress, there would be no need for the actual constitution of several distinct chambers; instead a complex voting formula could be used in a unitary organ, requiring the attainment of simultaneous majorities (which need not even be the same ones) on the basis of several different weightings. For the reasons already given, however, no serious consideration has yet been or in the foreseeable future is likely to be given to a solution along this line.

What is increasingly emerging is a qualified consensus rule. By itself, a consensus requirement constitutes something of a reversion to the classical unanimity principle that was the typical rule for international organs and conferences until the First World War and largely even until the Second. It may be defined briefly as taking a decision only when no participant opposes it so strongly as to insist on blocking it; a consensus can thus bridge wide, though not all too deep, differences. But since an unqualified consensus rule still permits any participant to exercise a veto, and thus, if determined and independent enough, to exact a high price for its agreement, the now frequently used qualified rule maintains the possibility of reverting to voting if the consensus process breaks down. This alternative is, however, resorted to only if the dissenters are considered to constitute a small, unreasonable and substantively overrideable minority. In practice, the threat to revert to voting is one merely maintained in the background to 
prevent any egregious abuse of the general desire to do business by consensus.

It cannot be denied that resort to any consensus rule does have disadvantages. One of these is the slowing of the entire process, as at each stage prolonged attempts must be made to overcome every genuine (even if objectively unreasonable) objection. Another is that the end product is likely to reflect not the best solution, or even the best that a majority could agree on, but rather the least common denominator of agreement-which may be low indeed. The countervailing advantage is, of course, some guarantee of general acceptability, which is important in view of the ultimate requirement that individual states ratify the treaty if it is to achieve legal status. The deliberateness of the process may also help to improve rather than degrade the product as solutions are found that compromise initially irreconcilable positions, and as individual governments utilize the delay to adjust to and accept new realities and regimes.

As can be seen, the decision-making process in international legislation is still evolving and no immediate breakthroughs seem likely. Nevertheless, as more experience is gained with variously adjusted rules, it may be hoped that improved procedures will emerge to balance the conflicting requirements of sovereign equality with a reasonable appreciation of the genuine disparity among states, and the desire for speed in resolving urgent problems with the necessity of proceeding with due deliberation.

\section{POST-ADOPTION}

On the domestic level the adoption of legislation concludes the legislative process, but internationally it only moves it to another and as yet quite unsatisfactorily functioning stage: securing of the agreement of individual states, generally referred to as ratification. Ratification is required for two purposes: for any given multilateral treaty a minimum level of participation is set (determined at the formulation stage, depending on the nature of the instrument and based on some estimate of political realities) before the treaty can enter into force at all; and in any event the treaty is, even after entry into force, generally binding only on those states that have ratified it.

There can be no doubt that this stage of the international legislative process is both crucial and unsatisfactory. ${ }^{5}$ Too many

- See the study by 0 . Schachter et. al, Wider Acceptance of Multilateral Treaties, UNITAR Series No. 2 (1969). 
treaties, born after long travail through the earlier stages, remain moribund for years while the minimum number of participants required for entry in force is assembled. Even more agreements are permanently enfeebled by a low level of participation, particularly by the absence of many powerful or otherwise significant states.

One source of the difficulty can be found on the international plane. Except in a few organizations, there is no systematic mechanism for following up on state action in respect of treaties formulated by the organization, except perhaps for sporadic reminders and pleas adopted by interested organs. Naturally, better results are achieved where the constitution of an international organization (e.g., of ILO and $\mathrm{WHO}^{6}$ requires member governments at least to initiate the domestic ratification process and to report periodically thereon to an international organ. In other cases, secretariats have been charged or have taken it on themselves to follow up on treaties, prodding governments and offering whatever assistance they can in overcoming domestic obstacles.

The real difficulty, however, lies with the generally quite inadequate domestic procedures for adopting or ratifying international legislation. On one hand, treaties are sometimes considered as if they were some species of domestic legislative proposals, subject to examination and improvement de novo, instead of being the largely unalterable (except through limited reservations or difficult amendments) end products of an already extensive legislative process. The inability to change these instruments, rather than accelerating their consideration, may lead to their being shunted aside indefinitely unless some strong domestic sponsor can be found. On the other hand, treaties may, as in the United States, be relegated to a traditional mechanism attuned not to the flood of law-making treaties of the 20th Century but to the occasional treaties of alliance of the $18 \mathrm{th}$, whose ratification was surrounded by special parliamentary safeguards and obstacles, but which now act as bottlenecks effectively preventing participation in a large body of international law. These national obstacles must await national remedies. Certainly the treaty-approval process, at least insofar as it relates to multilateral legislative instruments,

- See Constitution of the International Labour Organisation, adopted Oct. 9, 1946, 62 Stat. 3485, T.I.A.S. No. 1868,15 U.N.T.S. 35, Article 19(5); Constitution of the World Health Organization, opened for signature July $22,1946,62$ Stat. 2679, T.I.A.S. No. 1808,14 U.N.T.S. 185, as amended 26 U.S.T. 990, T.I.A.S. 8086, Article 20. 
should be freed of any special constraints inappropriate to it. At the same time, it may be necessary to involve selected members of national legislatures in the international process from an early stage, so that their ideas for changes and improvements can be tested in the competent international fora while instruments may still be changed. Then, after their having participated in the international formulation, it may be hoped that these legislators will ease the process of domestic approval.

Here too, an up-to-date inventory of law-making treaties, including those in force and those awaiting approval by states, would probably be helpful both on the international and the national plane. Such a list, with an indication of which states are eligible to but have not yet taken steps to participate in particular treaties, could by its very existence serve as a spur to national action and also alert international organizations to the states they should approach to urge ratification.

Finally, some mention should be made of certain limited exceptions to the generally rigid requirement of individual ratifications for treaties to achieve legal force. One of these has become common in respect to the constitutions of international organizations, which are amended much like other types of treaties are made or amended, except that the amendment usually enters into force for all members of the organization as soon as the specified number of ratifications (usually two-thirds) has been attained, thus binding even those that did not ratify the change; ${ }^{7}$ generally, however, they then have the option of withdrawing from the organization. The reasons for this exception are the absolute necessity of preserving the legal unity of a constitution and the undesirability of delaying each change until all members have individually consented. Another exception, which in a sense goes still further, permits some technical organizations to adopt regulations that thereupon enter into force for all members, though usually permitting them to opt out by giving a specific notification. ${ }^{8}$ Both of these procedures may be helpful harbingers of developments in this final stage of the international legislative process, but it is probably illusionary to hope that states will soon consent to any general substitution of these narrow and limited exceptions for the usual requirement of individual ratification.

7 See WHO Constitution, supra note 6, at Article 73.

- See WHO Constitution, supra note 6, at Article 22. 


\section{CONCLUSION}

It may confidently be expected that during the next decades significant improvements in the international legislative process will occur. Some of these will, no doubt, evolve through trial and error, as individual organizations strive to improve their procedures to accord with the perceived necessivies of the time. It may, however, be hoped that such inchoate groping for better methods may be guided and speeded with the aid of systematic studies of the legislative process, such as those recently initiated by the General Assembly and by the International Law Association. Although such improvements may not actually achieve, they may at least bring us closer to, Tennyson's vision of a parliament of man, in which the common sense of most creates universal law. ${ }^{9}$

- Tennyson, LoCKSLEy HALL, lines 128-30 (1842). 
. 